\title{
Immunoregulation of Dendritic Cells
}

\author{
Mark A Wallet, Pradip Sen, PhD, and Roland Tisch, PhD
}

\begin{abstract}
The paradigm of tolerogenic/immature versus inflammatory/mature dendritic cells has dominated the recent literature regarding the role of these antigen-presenting cells in mediating immune homeostasis or self-tolerance and response to pathogens, respectively. This issue is further complicated by the identification of distinct subtypes of dendritic cells that exhibit different antigen-presenting cell effector functions. The discovery of pathogen-associated molecular patterns and toll-like receptors provides the mechanistic basis for dendritic cell recognition of specific pathogens and induction of appropriate innate and adaptive immune responses. Only recently has insight been gained into how dendritic cells contribute to establishing and/or maintaining immunological tolerance to self. Soluble and cellular mediators have been reported to effectively regulate the function of dendritic cells by inducing several outcomes ranging from non-inflammatory dendritic cells that lack the ability to induce $T$ lymphocyte activation to dendritic cells that actively suppress $T$ lymphocyte responses. A thorough discussion of these stimuli and their outcomes is essential to understanding the potential for modulating dendritic cell function in the treatment of inflammatory disease conditions.
\end{abstract}

Keywords: Dendritic cells; Immunoregulation; Tolerance; IL- I0; Apoptosis; TGF- $\beta$; CTLA-4; CD200

$\mathrm{D}$

endritic cells have long been recognized as highly potent antigen-presenting cells. Upon activation, dendritic cells process and present antigens and express high levels of costimulatory and major histocompatibility complex (MHC) molecules, in addition to secreting various cytokines and chemokines which initiate and/or enhance many T and B lymphocyte responses. ${ }^{1}$ These responses include: 1) induction of $\mathrm{CD}^{+} \mathrm{T}$ lymphocyte type 1 and type 2 subset differentiation, ${ }^{1-3}$ 2) CD $8^{+} \mathrm{T}$ lymphocyte activation and enhancement of cytotoxic T lymphocyte activity ${ }^{4}$ and 3) B lymphocyte maturation, Ig class-switching and antibody production. 5,6 Only recently, however, has the tremendous versatility of dendritic cells become apparent. Beyond simple antigen capture, presentation and costimulation, dendritic cells play a unique role in tailoring selective immune responses to individual classes of pathogens. ${ }^{7,8}$ Additionally, dendritic cells are important mediators of peripheral immune tolerance and maintenance of immune homeostasis. ${ }^{9}$ In the past, these contrasting roles of dendritic cells have been described primarily as a function of maturation where immature dendritic cells were largely considered to be non-inflammatory or tolerogenic, but mature dendritic cells were considered capable of eliciting proinflammatory responses. Although generally correct, this paradigm is now proving to be too simple.
Dendritic cells arising from myeloid- or lymphoid-derived precursors exhibit an immature phenotype characterized by a high phagocytic capacity and low expression of costimulatory molecules such as CD40, CD80 and CD86. ${ }^{10}$ The many phagocytic receptors of dendritic cells allow ingestion of a wide variety of antigens including microbial pathogens or necrotic tissue laden with microbial antigens. Adhesion to, and phagocytosis of microbes by dendritic cells are dependent on several receptors including CD14, scavenger receptor-A (SR-A) ${ }^{11}$ and the Fc receptors (FcR): Fc $\gamma R 1, F c \gamma R 2 b$ and Fc $\gamma$ RIII. ${ }^{12-14}$ These pathways of phagocytosis lead to antigen processing mechanisms that load microbial peptides typically onto $\mathrm{MHC}$ class II for presentation to $\mathrm{CD}^{+} \mathrm{T}$ lymphocytes. Notably, dendritic cells defined by expression of CD8 $\alpha$ are also efficient in shuttling phagocytosed antigens into the MHC class I pathway and presentation to $\mathrm{CD} 8^{+} \mathrm{T}$ lymphocytes. ${ }^{15,16}$ Upon phagocytosis and subsequent activation, dendritic cells found residing in peripheral tissues traffic to the draining lymph nodes, undergo further maturation, and present to and stimulate $\mathrm{T}$ lymphocytes specific for the cognate peptide.

Several factors can induce dendritic cell maturation and promote a proinflammatory phenotype. For example, pathogen-associated molecular patterns-containing

Received: November 30, 2004

Revised: February 24, 2005

Accepted: May 13, 2005 
Table 1. Multiple subsets of murine splenic dendritic cells perform specialized functions. ${ }^{20}$

\begin{tabular}{|c|c|c|}
\hline Dendritic cell subset & Markers & Function \\
\hline Myeloid & $\begin{array}{l}\text { CD11c } \mathrm{c}^{+} \mathrm{CD} 205^{-\mathrm{CD}} 11 \mathrm{~b}^{+} \\
\mathrm{CD}^{-} \alpha^{-} \mathrm{CD} 4^{+/-}\end{array}$ & $\begin{array}{l}\text { Located in splenic marginal } \\
\text { zones. Efficient stimulation of } \\
\text { CD4 }{ }^{+} \text {and } C D 8^{+} T \text { cells. Favor } \\
\text { Th2 differentiation during } \\
\text { inflammatory conditions. }\end{array}$ \\
\hline Lymphoid & $\begin{array}{l}\text { CD } 11 c^{+} C D 205^{+} \mathrm{CD}_{11} \mathrm{~b}^{-} \\
\mathrm{CD} 8 \alpha^{+} \mathrm{CD}^{-}\end{array}$ & $\begin{array}{l}\text { Efficiently cross-present } \\
\text { exogenous antigens to CD8 }{ }^{+} \text {CTL. } \\
\text { Favor Th1 differentiation during } \\
\text { inflammatory conditions. Maintain } \\
\text { cross-tolerance to self antigens. }\end{array}$ \\
\hline Plasmacytoid & $\begin{array}{l}\text { CD } 11 c^{+} \text {CD } 11 b^{-} B 220^{+} \\
\mathrm{GR}^{+/-}\end{array}$ & $\begin{array}{l}\text { Possibly contribute to peripheral } \\
\text { self-tolerance. Mediate anti-viral } \\
\text { responses through production of IFN- } \alpha \text {. }\end{array}$ \\
\hline
\end{tabular}

components of bacteria, viruses and parasites, such as lipopolysaccharides, peptidoglycans, $\mathrm{CpG}$ motifs, flagella and viral nucleic acids, induce toll-like receptor signaling which results in dendritic cell maturation. ${ }^{17}$ Maturation of dendritic cells is crucial for the induction of $\mathrm{T}$ lymphocyte immunity as demonstrated by Hugues et al. ${ }^{18}$ This group determined that dendritic cell maturation due to inflammatory stimuli, such as lipopolysaccharide, results in prolonged contacts between dendritic cells and $T$ lymphocytes. The kinetics of this interaction differ from those observed for immature dendritic cells in which only short-term contacts with $\mathrm{T}$ lymphocytes are established. Interestingly, the extended contact between $\mathrm{T}$ lymphocytes and mature dendritic cells resulted in efficient $\mathrm{T}$ lymphocyte activation and proliferation not observed with immature dendritic cells. It is likely that the kinetics of dendritic cell/T lymphocyte interactions, along with dendritic cell phenotype (i.e., costimulatory molecule and cytokine expression) together determine whether immunity or tolerance is established. In addition to the kinetics of $\mathrm{T}$ lymphocyte interaction, dendritic cell maturation is crucial for appropriate migration to lymph nodes. Dendritic cells, which are matured by inflammatory stimuli in the periphery, become highly motile and readily migrate to local lymph nodes. Once in a lymph node, these mature dendritic cells settle within a network of unactivated dendritic cells near the $\mathrm{T}$ lymphocyte rich regions. This selective migration allows the dendritic cells to interact with vast numbers of $\mathrm{T}$ lymphocytes, thus enhancing $\mathrm{T}$ lymphocyte priming and activation. ${ }^{19}$

Toll-like receptor expression by dendritic cells serves multiple purposes. First, bodies that are phagocytosed in the presence of toll-like receptor signaling enter a specific phagosome maturation pathway. This pathway results in enhanced degradation of the engulfed material and efficient presentation of antigens. ${ }^{20}$ Secondly, dendritic cell subsets express unique repertoires of toll-like receptors, allowing for specialized responses to each class of pathogen. ${ }^{8}$ For instance, plasmacytoid dendritic cells uniquely express TLR9 and TLR7 which allow plasmacytoid dendritic cells to respond to viral $\mathrm{CpG} \mathrm{DNA}^{21,22}$ and viral single stranded
RNA, respectively. However, plasmacytoid dendritic cells do not express TLR4 and therefore respond to lipopolysaccharide relatively weakly. In plasmacytoid dendritic cells, TLR9 ligation results in high production of type I interferons (IFN- $\alpha$ and IFN- $\beta$ ) promoting plasmacytoid dendritic cell survival and increased MHC expression by neighboring antigen-presenting cells, thus enhancing anti-viral immunity. Through selective toll-like receptor expression, plasmacytoid dendritic cells are able to mount appropriate anti-viral responses. Meanwhile, responses to bacterial infections may primarily be mediated by $\mathrm{CD} 11 \mathrm{c}^{+} \mathrm{CD} 11 \mathrm{~b}^{+}$myeloid dendritic cells that express TLR4. Throughout the dendritic cells family, engagement of the various toll-like receptors results in production of several proinflammatory cytokines, including type I interferons, tumor necrosis factor (TNF)- $\alpha$, IFN- $\gamma$, IL-12 and IL-1. ${ }^{8}$ These unique responses, tailored by each dendritic cell subset, serve to enhance innate immune responses at the site of inflammation and guide adaptive immunity. The characteristics of murine dendritic cell subsets have been thoroughly reviewed by Wilson and $\mathrm{O}^{\prime} \mathrm{Neill}^{23}$ and are summarized in Table 1.

The above pattern-response mechanisms driving inflammation and adaptive immunity to pathogens have established a paradigm for recognition of non-self molecules. Overlooked until recently, however, is the role dendritic cells play in preventing autoreactivity and/or tolerizing existing autoreactive $\mathrm{T}$ cells. Therapies for autoimmune disorders and anti-graft rejection treatments have traditionally relied upon broadly immunosuppressive drugs, such as corticosteroids. Currently, strategies are being developed whereby individual cell types, such as dendritic cells, can be manipulated ex vivo to induce immune tolerance in a more antigen-specific manner. For the purpose of this review, we will focus on key soluble and cellular immunoregulators that are relevant in vivo, and which effectively promote a "tolerogenic" phenotype in dendritic cells. The discussion will include the cytokines IL-10 and transforming growth factor-beta (TGF- $\beta$ ), in addition to the role of apoptotic cells and signaling molecules such as CD80, CD86 and CD200R in dendritic cell immunoregulation. While not inclusive of the many 
mechanisms of dendritic cell immunoregulation, these topics capture the diversity of dendritic cell immunoregulation and highlight potential targets for new therapies.

\section{Immunoregulation of Dendritic Cells by IL- I0}

The local cytokine environment is an important contributor to the establishment of dendritic cell phenotype. IL-10, a major anti-inflammatory cytokine, is produced predominantly by $\mathrm{T}$ lymphocytes, monocytes, and macrophages. ${ }^{24}$ Treatment of immature dendritic cells with IL-10 in vitro induces an immunoregulatory phenotype that results in inhibition of $\mathrm{CD} 4^{+}$and $\mathrm{CD} 8^{+} \mathrm{T}$ lymphocyte reactivity in an antigen-specific manner. ${ }^{25-27}$ Among $\mathrm{CD}^{+} \mathrm{T}$ lymphocytes, both Th1 and Th2 responses can be inhibited by IL-10 treated dendritic cells. ${ }^{28}$ Similarly, IL-10 treated dendritic cells mediate tolerance within $\mathrm{CD}^{+}$cytotoxic $\mathrm{T}$ lymphocytes.

IL-10 pretreatment effectively inhibits maturation of immature dendritic cells. Upon lipopolysaccharide stimulation, human and murine IL-10 treated dendritic cells fail to 1) secrete proinflammatory cytokines including IL-1 $\beta$, IL-6, IL-12p70, and TNF- $\alpha$, 2) upregulate expression of costimulatory molecules such as CD40, CD80 and CD86 and 3 ) induce T-lymphocyte proliferation in allogeneic mixed lymphocyte reactions. ${ }^{27-31}$ Studies have demonstrated, however, that the tolerogenic effect of IL-10 treated dendritic cells is not simply due to decreased cytokine production or costimulatory molecule expression. Manavalan et al. ${ }^{32}$ reported that IL-10 treatment induced upregulation of the inhibitory immunoglobulin-like transcript 3 (ILT3) and ILT4 (LIR-2) molecules on the surface of human peripheral blood mononuclear cell-derived dendritic cells. Importantly, IL-10 treated dendritic cells no longer induced T lymphocyte anergy upon treatment with blocking antibodies specific for ILT3 and ILT4. Furthermore, murine fibroblast L transfectants expressing ILT4 induced T lymphocyte proliferation, suggesting that the inhibitory effect of ILT4 is in fact dendritic cell-specific. ${ }^{33}$ Evidence indicates that engagement of ILT4 by $\mathrm{T}$ lymphocytes promotes signaling within dendritic cells necessary for establishing an immunoregulatory phenotype. Interestingly, lipopolysaccharide stimulation of dendritic cells has also been found to elicit production of a soluble ILT4 molecule that enhances $T$ lymphocyte activation. Soluble ILT4 may competitively block T lymphocyte binding of membrane bound ILT4 to favor a stimulatory dendritic cell phenotype. On the other hand, IL-10 treated dendritic cells upon lipopolysaccharide treatment fail to express soluble ILT4 which would be expected to further promote the tolerogenic capacity of IL-10 treated dendritic cells. ${ }^{33}$ Interestingly, donor dendritic cells expressing ILT3 and ILT4 are associated with reduced rejection of murine heart transplants. ${ }^{34}$ The immunoregulatory properties of IL-10 upon dendritic cells are summarized in figure 1.

Although ineffective at mediating $\mathrm{T}$ lymphocyte activation, Nolan et al. ${ }^{35}$ demonstrated that murine IL-10 treated dendritic cells maintain the capacity to elicit innate immune

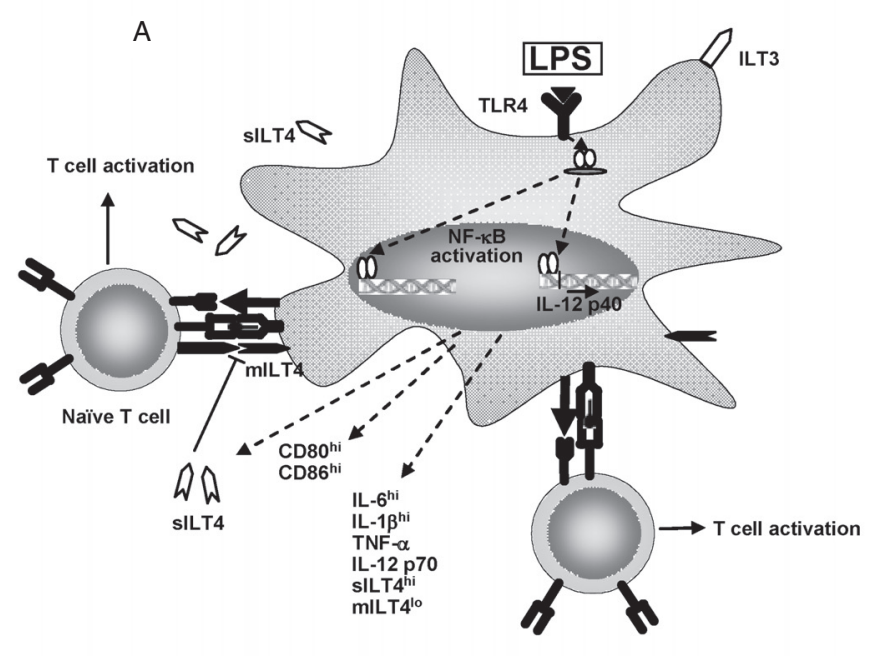

Effector $\mathrm{CD4}^{+} \mathrm{T}$ cell

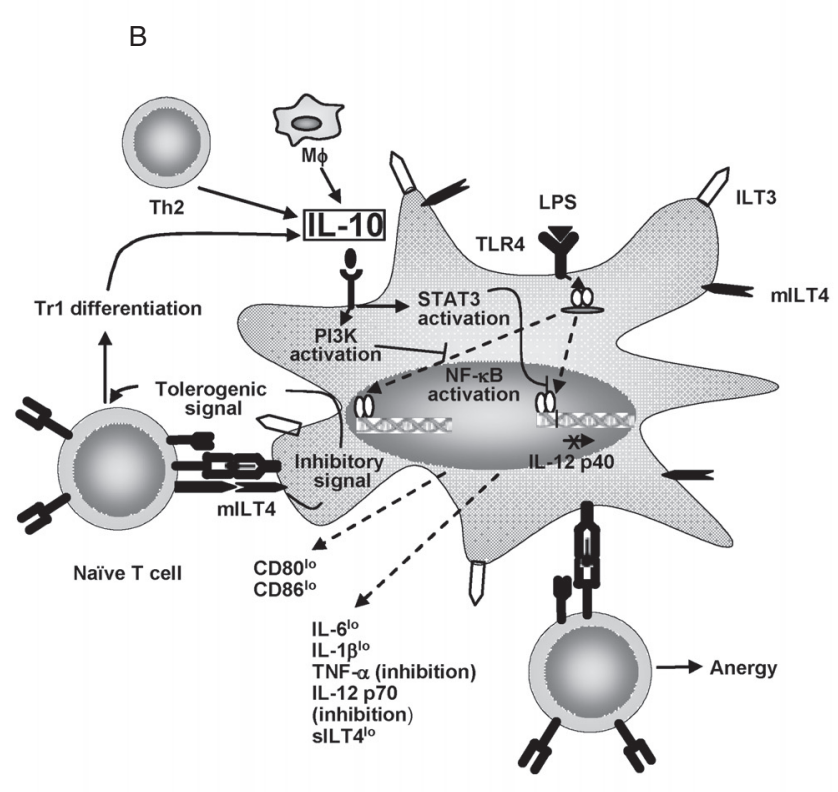

Effector $\mathrm{CD}^{+} \mathrm{T}$ cell

Figure 1. IL-10 induces immunoregulation of dendritic cell maturation. (A) Lipopolysaccharide promotes $\mathrm{T}$ cell activation. When immature dendritic cells encounter inflammatory stimuli, such as lipopolysaccharide, maturation ensues. NF- $\kappa B$ is activated, translocated to the nucleus and transcription of multiple genes is induced. Costimulatory molecules CD80 and CD86, inflammatory cytokines (IL-6, IL-1 $\beta$, TNF- $\alpha$ and IL-12p70) and soluble ILT4 (soluble LIR2) are produced which support activation of $T$ cells. (B) IL-10 blocks the effects of lipopolysaccharide upon dendritic cells. IL-10 produced by monocytes, TH2 cells and Tr1 cells induces PI3K and signal transducer and activator of transcription (STAT)-3 activation by dendritic cells. PI3K activation results in blockade of NF- $\mathrm{KB}$ activation and STAT-3 blocks binding of NF- $\kappa B$ to the IL-12p40 promoter. Consequently, differentiation of Th1 T lymphocytes is inhibited. Additionally, IL-10 inhibits production of soluble ILT4 favoring expression of membrane bound ILT4. Ligation of dendritic cell membrane bound ILT4 by $\mathrm{T}$ lymphocytes induces a regulatory dendritic cell phenotype that induces Tr1 differentiation. 
responses to microbial pathogens. Following stimulation with lipopolysaccharide of IL-10 pretreated dendritic cells, the authors demonstrated unaffected or upregulated production of proinflammatory molecules DCIP-1, MIP-2, CXCL-4, CXCL-5, IL-1 and phagocytosis-associated protein by application of reverse transcription-polymerase chain reaction and serial analysis of gene expression. These factors typically enhance recruitment and activation of neutrophils and phagocytosis of microbial debris, both of which are essential components of innate immunity. Consequently, IL-10 treated dendritic cells continue to mediate a proinflammatory response and clearance of pathogens. This work has helped to establish a paradigm whereby dendritic cell tolerance may simply not be a question of "on versus off" but rather "adaptive versus innate." Future analysis of transcriptional regulation induced by IL-10 may shed light upon the molecular switches that induce global changes in the ability of dendritic cells to mediate specific responses.

IL-10 clearly induces phenotypic changes in dendritic cells, but the signaling events mediating these outcomes remain largely unknown. Recent findings indicate that IL-10 can induce phosphoinositol-3 kinase and signal transducer and activator of transcription 3-dependent inhibition of NF- $\mathrm{kB}$ function $^{30,36}$ in dendritic cells. NF- $\mathrm{\kappa B}$ is a key transcription factor that regulates various aspects of dendritic cell development, maturation and effector function including MHC expression, IL-12 and TNF- $\alpha$ production. Phosphoinositol-3 kinase activation in response to IL-10 treatment results in downstream blockade of NF- $\mathrm{KB}$ activation..$^{30}$ Notably, the inhibitory effect of IL-10 on dendritic cells in vitro is generally detected only after 12 to 24 hours of pretreatment. ${ }^{30}$ The latter indicates de novo synthesis of protein(s), which is necessary to block NF- $\mathrm{KB}$ activation by stimuli such as lipopolysaccharide and CD40 engagement. Additionally, signal transducer and activator of transcription-3 activation in response to IL-10 results in direct inhibition of $\mathrm{NF}-\mathrm{KB}$ binding to the IL-12p40 promoter sequence. ${ }^{36}$ Importantly, the effects of IL-10 on signaling are distinct between macrophages and dendritic cells, and possibly between subsets of dendritic cells. Further research into the signaling mechanisms that control immunoregulatory dendritic cell differentiation is warranted.

The many observations that IL-10 modulates dendritic cell effector function in a tolerogenic manner have spurred studies to assess the efficacy of using IL-10 treated dendritic cells to treat inflammatory disorders. Initial results have been promising and suggest that so-called dendritic cell "vaccines" may be useful in the treatment of various autoimmune diseases and prevention of allogeneic organ graft rejection. 37,38 In addition, groups have engineered dendritic cells to express high levels of IL-10. Upon adoptive transfer, such dendritic cells preferentially traffic to sites of inflammation enhancing the anti-inflammatory properties of IL-10. For example, Coates et al. ${ }^{37}$ transduced human myeloid dendritic cells with an adenoviral recombinant

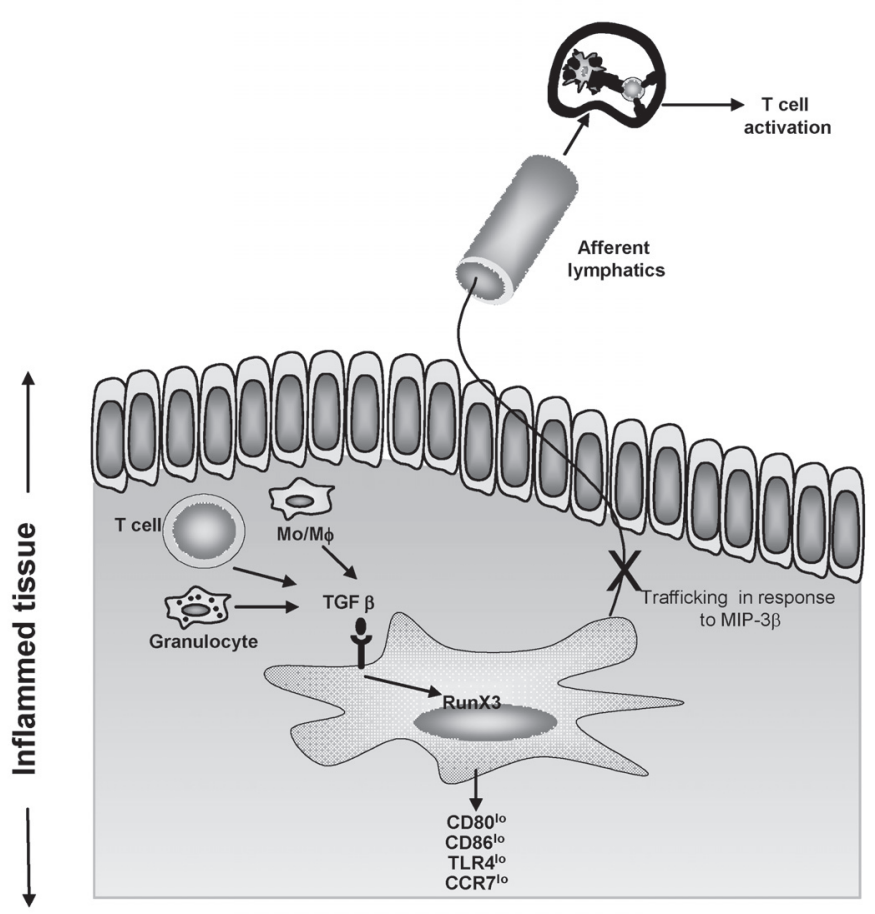

Figure 2. TGF- $\beta 1$ modulated dendritic cell phenotype and $T$ lymphocyte activation. TGF- $\beta 1$ is produced by monocytes or macrophages, $\mathrm{T}$ lymphocytes or granulocytes, or is provided exogenously as a means of immunotherapy. Dendritic cells that encounter TGF- $\beta 1$ down-regulate expression of CD80, CD86, TLR4 and, importantly, CCR7. Low expression of CCR7 inhibits MIP-3 $\beta$-induced migration to lymph nodes. Therefore, T lymphocyte stimulation is inhibited.

encoding IL-10 gene (AdvIL-10) which upon transfer into a humanized non-obese diabetic (NOD) scid mouse model effectively protected human skin grafts.

\section{The Role of TGF- $\beta$ I in Regulating Dendritic Cells}

TGF- $\beta 1$ belongs to a well-defined multipotent cytokine family known to regulate several patho-physiological events. TGF- $\beta$ of $\mathrm{T}$ lymphocyte, monocyte/macrophage or granulocyte origin is typically detected at sites of inflammation. ${ }^{39}$ Among the three isoforms of TGF- $\beta$, TGF- $\beta 1$ exhibits the broadest spectrum of biological activities. Notably, TGF- $\beta 1$ promotes early dendritic cell development in vitro and suppression of immature dendritic cell activation and maturation. ${ }^{40,41}$ For example, TGF- $\beta 1$ inhibits upregulation of the costimulatory molecules CD83 and CD86 in humans $\mathrm{s}^{42}$ and $\mathrm{CD} 80$ and $\mathrm{CD} 86$ in mice, ${ }^{43}$ thereby reducing the efficacy of dendritic cells to stimulate $\mathrm{T}$ lymphocytes.

One mechanism that contributes to impaired capacity of TGF- $\beta 1$-treated dendritic cells for $\mathrm{T}$ lymphocyte stimulation may be the down-regulation of key immunomodulatory receptors. Mou et al. ${ }^{44}$ observed that in vitro treatment of murine bone marrow-derived dendritic cells with TGF- $\beta 1$ resulted in decreased expression of TLR4. This finding correlated with reduced sensitivity to lipopolysaccharide-induced maturation. Interestingly, Tada et al. ${ }^{45}$ found that TGF- $\beta$ treatment of murine Langerhans cells or bulk splenic CD11 $\mathrm{c}^{+}$ dendritic cells inhibited the ability of these cells to produce 
IL-6 and IL-12 in response to lipopolysaccharide. The inability to recognize proinflammatory microbial products combined with decreased signaling capacity likely renders TGF- $\beta 1$-treated dendritic cells ineffective in driving $\mathrm{T}$ lymphocyte immunity.

Additionally, TGF- $\beta 1$ affects the trafficking of mature dendritic cells (figure 2). For example, Ogata et al. ${ }^{46}$ reported that TGF- $\beta 1$ inhibits dendritic cell expression of the chemokine receptor CCR7. CCR7 is a key receptor for dendritic cell migration in response to the chemokines CCL19 (MIP3 $\beta$ ) and CCL21. Dendritic cells lacking expression of CCR7 due to the introduction of a null mutation in mice cannot migrate to lymph nodes in response to MIP3 $\beta$ or CCL21. ${ }^{47}$ Similarly, TGF- $\beta 1$ conditioned dendritic cells are impaired in their ability to migrate to lymph nodes in response to inflammatory chemokines and $\mathrm{T}$ lymphocyte stimulation is subsequently inhibited. The molecular targets of TGF- $\beta 1$ mediated suppression in dendritic cells remain ill defined. One such target, however, appears to be the transcription factor RunX3. For example, dendritic cells lacking expression of RunX3 are resistant to the immunoregulatory effects of TGF- $\beta 1.48$

Several strategies of immunotherapy have focused on the immunoregulatory properties of TGF- $\beta 1$ upon dendritic cell maturation and effector function. Yarilin et al. ${ }^{49}$ employed TGF- $\beta 1$-treated dendritic cells to successfully suppress experimental autoimmune myasthenia gravis, an animal model of myasthenia gravis. Both experimental autoimmune myasthenia gravis and myasthenia gravis pathologies are the result of $\mathrm{T}$ lymphocyte-dependent antibody responses to the acetylcholine receptor. Adoptive transfer of splenic dendritic cells pretreated with TGF- $\beta 1$ to Lewis rats immunized with acetylcholine receptor protein effectively suppressed ongoing experimental autoimmune myasthenia gravis, resulting in reduced mortality and a diminished frequency of anti-acetylcholine receptor antibody producing cells. Others have utilized TGF- $\beta 1$-expressing adenoviral vectors to modify dendritic cell function. These studies have consistently reported the ability of adenoviral vector-transduced dendritic cells to inhibit syngeneic and allogeneic $\mathrm{T}$ cell responses. ${ }^{50,51}$ This inhibition includes dominant suppression of allogeneic $\mathrm{CD}^{+}$ and $\mathrm{CD}^{+} \mathrm{T}$ effectors that have been primed by untreated dendritic cells. 52

\section{Dendritic Cells and Immune Homeostasis - The Role of Apoptotic Cells}

Dendritic cell activation is typically referred to in the context of a response to pathogens. Unperturbed environments foster maintenance of immature dendritic cells, while microbial pathogens induce differentiation to a specific mature/activated phenotype. This representation of dendritic cell life cycle accurately represents a portion of immune regulation, but the model fails to address the activity of dendritic cells under homeostatic conditions. Multicellular organisms constantly harbor a mixed balance of viable, apoptotic and necrotic

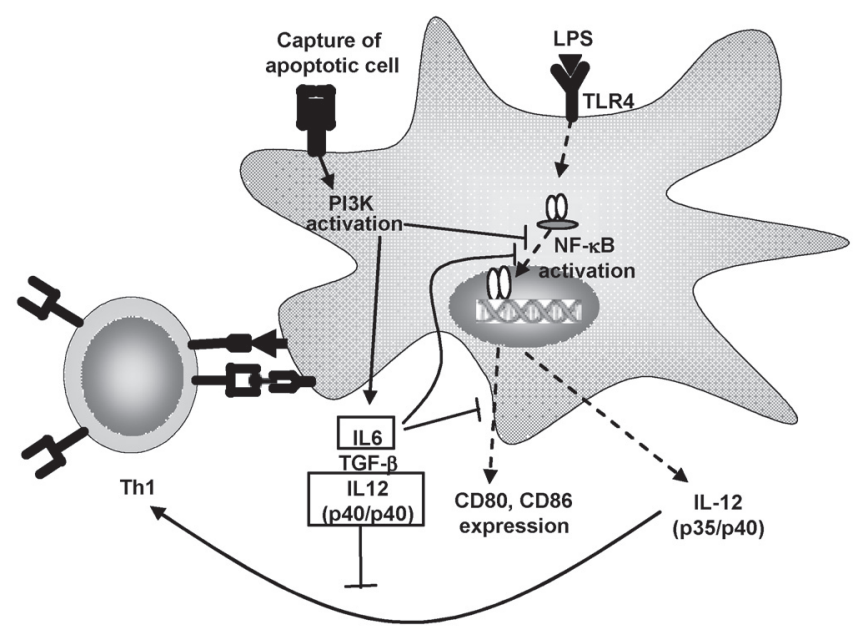

Figure 3. Apoptotic cells induce immunoregulation and tolerance induction through dendritic cells. Dendritic cells scavenge tissues for microbes and dying tissue. Apoptotic cells induce PI3K dependent signaling resulting in inhibition of NF- $\mathrm{KB}$ translocation and costimulatory molecule (CD80/86) expression. Production of IL-6, TGF- $\beta$ and IL-12p40 ensue. IL-12p40 homodimers inhibit the effects of IL-12p70 upon T lymphocytes, effectively inhibiting Th1 induction. Apoptotic cells induce a lasting inhibitory effect which renders dendritic cells refractory to lipopolysaccharide-induced stimulation of Th1 lymphocytes.

tissues. The continual exposure to self-antigen necessitates appropriate regulation of dendritic cell maturation and effector function in order to maintain immunological tolerance.

The clearance of apoptotic cells in vivo is carried out by multiple phagocytes, including macrophages, neutrophils and dendritic cells. In the case of dendritic cells, it is only immature cells that are capable of apoptotic cell phagocytosis. Binding and ingestion of apoptotic cells by immature dendritic cells is mediated by a group of receptors, including phosphatidylserine receptor, $53 \alpha_{\mathrm{V}} \beta_{5}$ integrin, ${ }^{15}$ complement receptor $\mathrm{C} 1 \mathrm{qR}$ and the receptor tyrosine kinase MerTK. ${ }^{54}$

In general, when dendritic cells encounter apoptotic cells, a non-inflammatory and tolerogenic phenotype typical of immature dendritic cells is observed. ${ }^{55}$ For example, Stuart et al. ${ }^{56}$ showed that dendritic cells pretreated with apoptotic cells exhibited a reduced capacity to produce IL-12p70 upon stimulation. Interestingly, the effect was selective in that secretion of TNF- $\alpha$ was unaltered. Immature dendritic cells treated with apoptotic cells also exhibit an impaired capacity to stimulate T lymphocytes. Additionally, Kim et al. ${ }^{57}$ have demonstrated that phosphatidylserine from apoptotic cells induces regulation of dendritic cell activation. Downstream events following apoptotic cell contact or phosphatidylserine contact with dendritic cells resulted in inhibition of IL-12p35 transcription and thus IL-12p70 synthesis. Notably, lipopolysaccharide treatment is unable to overcome the tolerogenic phenotype, indicating the effect of apoptotic cells is long-lasting and relatively stable. ${ }^{55}$ As a result, activation of dendritic cells carrying the remnants of apoptotic cells is effectively prevented. Takahashi and Kobayashi ${ }^{58}$ reported 
that, in addition to maintaining an immature phenotype, exposure to apoptotic cells induced the expression of IL-6 and IL-12p40 further enhancing the tolerogenic function of the dendritic cells. Apoptotic cell-induced IL-6 secretion by dendritic cells functions in an autocrine manner to block further maturation of dendritic cells. For example, activation of signal transducer and activator of transcription-3 following IL-6 pretreatment blocks lipopolysaccharide-induced upregulation of CD80, CD86, CD40, and MHCII thereby reducing the $\mathrm{T}$ lymphocyte stimulatory capacity of the dendritic cells. Furthermore, IL-6 has been reported to suppress TNF- $\alpha$ and peptidoglycan-mediated activation and maturation of dendritic cells. On the other hand, secretion of significant levels of IL-12p40 results in formation of IL-12p40 homodimers which competitively inhibit IL-12p70 binding to the IL-12 receptor on T lymphocytes. ${ }^{59}$ Consequently, differentiation of naïve $\mathrm{T}$ lymphocytes into type 1 effectors is suppressed (figure 3).

Sauter et al. 60 have described how phagocytosis of apoptotic cells by dendritic cells affects cross-presentation of self-antigens to $\mathrm{CD}^{+} \mathrm{T}$ lymphocytes. Employing human dendritic cells and apoptotic versus necrotic 293 tumor cells, the importance of the mode of death of the phagocytosed cells was initially defined. Necrotic, but not apoptotic 293 cells induced dendritic cell maturation based on upregulation of CD83 and dendritic cell-lysosome-associated membrane glycoprotein.

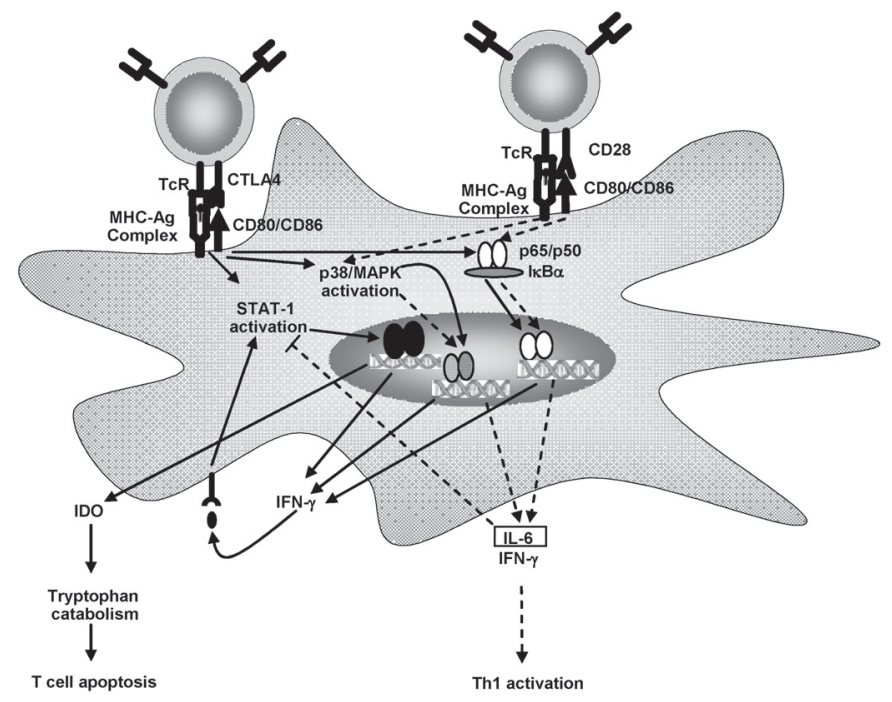

Figure 4. CTLA-4 and CD28 induce divergent outcomes in dendritic cell maturation. Regulatory $T$ lymphocyte cells expressing CTLA-4 ligate CD80 on dendritic cells inducing STAT-1 activation, IFN- $\gamma$ and IDO production. IDO catalyzes the breakdown of tryptophan resulting in $\mathrm{T}$ lymphocyte activation followed by rapid induction of apoptosis. In contrast, activated T lymphocytes expressing CD28 induce activational signals through CD80/CD86. Receptor ligation induces p38 MAPK and NF- $\kappa B$ activation. IL- 6 and IFN- $\gamma$ are then produced. IL- 6 induces a dominant antagonistic effect upon IDO production. Dendritic cells are now capable of inducing $T$ lymphocyte activation and proliferation.
Furthermore, pulsing dendritic cells with necrotic allogeneic splenocytes resulted in a mixed lymphocyte reaction. In contrast, apoptotic allogeneic splenocytes failed to induce a significant mixed lymphocyte reaction. Furguson et al.61 demonstrated the potent effects of apoptotic cells on dendritic cell effector function in vivo. Injection of apoptotic splenocytes coupled with trinitrophenol blocked in vitro recall responses to the hapten. Importantly, $\mathrm{CD} 11 \mathrm{c}^{+} \mathrm{CD} 8 \alpha^{+}$ dendritic cells were identified as the critical effectors for inducing the immune tolerance to apoptotic cell antigens.

The above observations are further supported by studies demonstrating that dendritic cell function is regulated by apoptotic cells. Stuart et al. ${ }^{56}$ demonstrated that apoptotic cells directly inhibit dendritic cell responses to bacterial endotoxin. The observed inhibition of IL-12p70 production and CD86 expression was not due to autocrine production of IL-10 or TGF- $\beta$ suggesting the existence of direct signaling mechanisms of dendritic cells that respond to apoptotic cell binding. $\mathrm{Xu}$ et al. ${ }^{62}$ showed the therapeutic potential of apoptotic cell induced tolerance of dendritic cells in a murine model of organ transplantation. Autologous dendritic cells were loaded with apoptotic cells from allogeneic cardiac graft donors. When apoptotic cell-treated dendritic cells were administered to the organ recipients, graft survival was enhanced. In contrast, Basu et al. ${ }^{63}$ demonstrated that necrotic, but not apoptotic cells, induced dendritic cell activation and maturation in an NF- $\mathrm{\kappa B}$-dependent manner. This balance in dendritic cell reactivity allows the peripheral immune system to continually monitor tissues for signs of death and mount the appropriate responses. The importance of dendritic cells in clearance of apoptotic cells and the maintenance of immune homeostasis are highlighted in autoimmune diseases, such as systemic lupus erythematosus. While not wholly causal for systemic lupus erythematosus, failure to effectively clear apoptotic cells contributes to the severity of disease. ${ }^{64}$

We have recently undertaken studies to describe the signaling mechanisms responsible for apoptotic cell-induced dendritic cell tolerance. Initial results suggest that apoptotic cells block proinflammatory stimuli through inhibition of the NF- $\kappa \mathrm{B}$ pathway. Specifically, in murine bone marrow-derived or splenic dendritic cells, pretreatment with apoptotic cells for 0.5 to 3 hours inhibits activation of $\mathrm{I} \kappa \mathrm{B}$ kinase and downstream NF- $\mathrm{KB}$ induced by lipopolysaccharide or CD40 engagement. By targeting the NF- $\mathrm{BB}$ pathway, which is critical for gene expression associated with dendritic cell activation and maturation, apoptotic cells effectively immunoregulate dendritic cell phenotype and function. Further analysis of the processes that mediate immune homeostasis by apoptotic cells will help define defects that contribute to autoimmunity, in addition to the development of rational modalities of immunotherapy for prevention and/or treatment of autoimmunity and other proinflammatory diseases. 


\section{Signaling via CD80 and CD86 Regulates Dendritic Cell Activation/Maturation}

$\mathrm{T}$ lymphocyte activity is frequently viewed as being dependent on interaction with dendritic cells or other antigen-presenting cells. Upon a cognate interaction, however, engagement by $\mathrm{T}$ lymphocytes of various cell surface molecules also induces signals that affect dendritic cell activation and/or maturation. For example, ligation of CD40 by CD40L expressed on the surface of $\mathrm{T}$ lymphocytes delivers a potent activational signal for dendritic cells. ${ }^{65-68}$ More recently, signals delivered by the costimulatory molecules CD80 and CD86 have been shown to modulate dendritic cell activation and effector function. ${ }^{69}$ Regulatory $\mathrm{T}$ lymphocytes express the surface molecule CTLA-4 which binds CD80 (and CD86) with high affinity. ${ }^{68}$ Following a cognate interaction between regulatory $\mathrm{T}$ lymphocytes and dendritic cells, CD80 was induced which included signal transducer and activator of transcription-1 activation and subsequent secretion of IFN- $\gamma{ }^{71}$ IFN- $\gamma$ has an immediate autocrine effect upon dendritic cells, resulting in the secretion of the enzyme indoleamine 2,3-dioxygenase (IDO) ${ }^{72}$ IDO is an enzyme that catalyzes the breakdown of the amino acid tryptophan into N-formyl-kynurenine and various downstream metabolites. Importantly, depletion of tryptophan in the surrounding milieu has a profound effect upon $\mathrm{T}$ lymphocytes which can be reversed experimentally by provision of exogenous tryptophan. ${ }^{73,74} \mathrm{~T}$ lymphocytes stimulated by peptide/MHC presented by IDO-producing dendritic cells undergo activation and then rapid cell death via apoptosis 75 (figure 4).

As is the case for most mechanisms of immune deviation, CTLA-4 induced tolerance can be countered. In a fashion quite similar to the CTLA-4/CD80 signaling axis, activated T lymphocytes provide dendritic cells with a proinflammatory feedback stimulus. Expression of CD28 by activated T lymphocytes serves to ligate CD86 on dendritic cells. ${ }^{76}$ This interaction induces a signaling cascade that results in p38 MAPK and NF- $\kappa B$ activation. ${ }^{71}$ Subsequently IFN- $\gamma$ and IL-6 are produced. In this scenario, however, IFN- $\gamma$ mediated induction of IDO is hampered by IL-6, which has been shown to dominantly block IFN- $\gamma$ induced IDO expression and block the regulatory capacity of these dendritic cells. ${ }^{75}$ Indeed, expression of IL-6 by dendritic cells in this case drives a dominant proinflammatory response, as opposed to serving a suppressive role as described above. This phenomenon further highlights the complexity of dendritic cell regulation and serves to warn against assignment of broad descriptive labels (i.e., regulatory) to cytokine activity. The nature of immune responses cannot be determined by the presence of individual cytokines. Instead, the entire milieu of cytokines, the initial stimulus for their production, the cell types present and the activation status of those cells present must all be considered to truly understand the nature of an immune response.
CD200R:A Novel Molecule Regulating Dendritic Cell Effector Function

A second model for IDO induction involves the widely expressed molecule CD200 (OX-2) and its receptor CD200R. ${ }^{77}$ Ligation of CD200R on splenic plasmacytoid dendritic cells results in IDO secretion and antigen-specific immunoregulation, which in turn is mediated via induction of regulatory $\mathrm{T}$ lymphocytes. ${ }^{78}$ The mechanism by which IDO secreting plasmacytoid dendritic cells induce regulatory $\mathrm{T}$ lymphocytes has yet to be defined. The ubiquitous nature of CD200 expression by non-immune cells suggests a role for CD200R-mediated tolerance in immune homeostasis. Furthermore, mice lacking CD200 expression demonstrated increased susceptibility to autoimmunity. 79,80 Manipulation of CD200/CD200R signaling may prove to be a novel mechanism for induction of antigen specific immune tolerance. Such a system could be beneficial for clinical treatment of many inflammatory diseases such as type 1 diabetes, rheumatoid arthritis and multiple sclerosis.

\section{Summary}

Scientists and clinicians have spent the better part of the past century attempting to manipulate the immune system. These efforts have primarily focused upon induction of immunity to pathogens. Currently, a major emphasis is on the development of effective immunotherapies for the prevention and/or suppression of proinflammatory responses associated with autoimmunity and transplantation. In view of their central role in eliciting and regulating immunity, the application of dendritic cells for the purpose of immunotherapy is highly appealing.

Initial studies using either IL-10-treated or TGF- $\beta 1$-treated dendritic cells to induce antigen-specific immune tolerance have shown promise. As we gain further mechanistic insight into events regulating dendritic cell maturation and effector function, the therapeutic efficacy of dendritic cell-based "vaccines" will be enhanced. Techniques that allow for harvest, ex vivo culture and re-infusion of autologous dendritic cells have already been developed. Together with advances in gene therapy, the use of dendritic cell-based vaccines may allow clinicians to manipulate the immune system in a safe and effective manner.

\section{References}

1. Alaniz RC, Sandall S, Thomas EK, Wilson CB. Increased dendritic cell numbers impair protective immunity to intracellular bacteria despite augmenting antigen-specific $\mathrm{CD}^{+} \mathrm{T}$ lymphocyte responses. J Immunol 2004;172:3725-3735.

2. Maldonado-Lopez R, Moser M. Dendritic cell subsets and the regulation of Th1/Th2 responses. Semin Immunol 2001;13:275-282.

3. Eisenbarth SC, Piggott DA, Bottomly K. The master regulators of allergic inflammation: dendritic cells in Th2 sensitization. Curr Opin Immunol 2003;15:620-626.

4. Smith CM, Wilson NS, Waithman J, Villadangos JA, Carbone FR, Heath WR, Belz GT. Cognate CD4(+) T cell licensing of dendritic cells in CD8(+) T cell immunity. Nat Immunol 2004;5:1143-1148. 
5. Gerloni M, Lo D, Zanetti M. DNA immunization in relB-deficient mice discloses a role for dendritic cells in IgM $\longrightarrow \operatorname{IgG1}$ switch in vivo. Eur J Immunol 1998;28:516-524.

6. MacPherson G, Kushnir N, Wykes M. Dendritic cells, B cells and the regulation of antibody synthesis. Immunol Rev 1999;172:325-334.

7. de Jong EC, Smits HH, Kapsenberg ML. Dendritic cellmediated T cell polarization. Springer Semin Immunopathol 2005;26:289-307.

8. Proietto AI, O'Keeffe M, Gartlan K, Wright MD, Shortman K, $\mathrm{Wu} \mathrm{L}$, Lahoud MH. Differential production of inflammatory chemokines by murine dendritic cell subsets. Immunobiology 2004;209:163-172.

9. Gad M, Claesson MH, Pedersen AE. Dendritic cells in peripheral tolerance and immunity. APMIS 2003;111:766775.

10. Mahnke K, Schmitt E, Bonifaz L, Enk AH, Jonuleit H. Immature, but not inactive: the tolerogenic function of immature dendritic cells. Immunol Cell Biol 2002;80:477-483.

11. van Oosten M, van de Bilt E, van Berkel TJ, Kuiper J. New scavenger receptor-like receptors for the binding of lipopolysaccharide to liver endothelial and Kupffer cells. Infect Immun 1998;66:5107-5112.

12. Tobar JA, Gonzalez PA, Kalergis AM. Salmonella escape from antigen presentation can be overcome by targeting bacteria to Fc gamma receptors on dendritic cells. J Immunol 2004;173:4058-4065.

13. Schuurhuis DH, Ioan-Facsinay A, Nagelkerken B, van Schip JJ, Sedlik C, Melief CJ, Verbeek JS, Ossendorp F. Antigen-antibody immune complexes empower dendritic cells to efficiently prime specific $\mathrm{CD} 8^{+} \mathrm{CTL}$ responses in vivo. J Immunol 2002;168:2240-2246.

14. Regnault A, Lankar D, Lacabanne V, Rodriguez A, Thery C, Rescigno M, Saito T, Verbeek S, Bonnerot C, Ricciardi-Castagnoli P, Amigorena S. Fcgamma receptor-mediated induction of dendritic cell maturation and major histocompatibility complex class I-restricted antigen presentation after immune complex internalization. J Exp Med 1999;189:371-380.

15. Albert ML, Pearce SF, Francisco LM, Sauter B, Roy P, Silverstein RL, Bhardwaj N. Immature dendritic cells phagocytose apoptotic cells via alphavbeta5 and CD36, and cross-present antigens to cytotoxic T lymphocytes. J Exp Med 1998;188:1359-1368.

16. Albert ML, Sauter B, Bhardwaj N. Dendritic cells acquire antigen from apoptotic cells and induce class I-restricted CTLs. Nature 1998;392:86-89.

17. Werling D, Jungi TW. TOLL-like receptors linking innate and adaptive immune response. Vet Immunol Immunopathol 2003;91:1-12.

18. Hugues S, Fetler L, Bonifaz L, Helft J, Amblard F, Amigorena $\mathrm{S}$. Distinct $\mathrm{T}$ cell dynamics in lymph nodes during the induction of tolerance and immunity. Nat Immunol 2004;5:1235-1242.

19. Lindquist RL, Shakhar G, Dudziak D, Wardemann H, Eisenreich T, Dustin ML, Nussenzweig MC. Visualizing dendritic cell networks in vivo. Nat Immunol 2004;5:1243-1250.

20. Blander JM, Medzhitov R. Regulation of phagosome maturation by signals from toll-like receptors. Science 2004;304:1014-1018.

21. Coccia EM, Severa M, Giacomini E, Monneron D, Remoli ME, Julkunen I, Cella M, Lande R, Uze G. Viral infection and Toll-like receptor agonists induce a differential expression of type I and lambda interferons in human plasmacytoid and monocyte-derived dendritic cells. Eur J Immunol 2004;34:796-805.
22. Ito T, Wang YH, Liu YJ. Plasmacytoid dendritic cell precursors/type I interferon-producing cells sense viral infection by Toll-like receptor (TLR) 7 and TLR9. Springer Semin Immunopathol 2005;26:221-229.

23. Wilson HL, O’Neill HC. Murine dendritic cell development: difficulties associated with subset analysis. Immunol Cell Biol 2003;81:239-246.

24. Moore KW, de Waal Malefyt R, Coffman RL, O'Garra A. Interleukin-10 and the interleukin-10 receptor. Annu Rev Immunol 2001;19:683-765.

25. Steinbrink K, Wolfl M, Jonuleit H, Knop J, Enk AH. Induction of tolerance by IL-10-treated dendritic cells. J Immunol 1997;159:4772-4780.

26. Steinbrink K, Jonuleit H, Muller G, Schuler G, Knop J, Enk $\mathrm{AH}$. Interleukin-10-treated human dendritic cells induce a melanoma-antigen-specific anergy in CD8(+) T cells resulting in a failure to lyse tumor cells. Blood 1999;93:1634-1642.

27. Yang AS, Lattime EC. Tumor-induced interleukin 10 suppresses the ability of splenic dendritic cells to stimulate CD4 and CD8 T-cell responses. Cancer Res 2003;63:2150-2157.

28. Haase C, Jorgensen TN, Michelsen BK. Both exogenous and endogenous interleukin-10 affects the maturation of bone-marrow-derived dendritic cells in vitro and strongly influences T-cell priming in vivo. Immunology 2002;107:489-499.

29. Harizi H, Norbert G. Inhibition of IL-6, TNF-alpha, and cyclooxygenase- 2 protein expression by prostaglandin E2-induced IL-10 in bone marrow-derived dendritic cells. Cell Immunol 2004;228:99-109.

30. Bhattacharyya S, Sen P, Wallet M, Long B, Baldwin AS Jr, Tisch R. Immunoregulation of dendritic cells by IL-10 is mediated through suppression of the PI3K/Akt pathway and of IkappaB kinase activity. Blood 2004;104:1100-1109.

31. McBride JM, Jung T, de Vries JE, Aversa G. IL-10 alters DC function via modulation of cell surface molecules resulting in impaired T-cell responses. Cell Immunol 2002;215:162-172.

32. Manavalan JS, Rossi PC, Vlad G, Piazza F, Yarilina A, Cortesini R, Mancini D, Suciu-Foca N. High expression of ILT3 and ILT4 is a general feature of tolerogenic dendritic cells. Transpl Immunol 2003;11:245-258.

33. Beinhauer BG, McBride JM, Graf P, Pursch E, Bongers M, Rogy M, Korthauer U, de Vries JE, Aversa G, Jung T. Interleukin 10 regulates cell surface and soluble LIR-2 (CD85d) expression on dendritic cells resulting in T cell hyporesponsiveness in vitro. Eur J Immunol 2004;34:74-80.

34. Chang CC, Ciubotariu R, Manavalan JS, Yuan J, Colovai AI, Piazza F, Lederman S, Colonna M, Cortesini R, Dalla-Favera R, Suciu-Foca N. Tolerization of dendritic cells by T(S) cells: the crucial role of inhibitory receptors ILT3 and ILT4. Nat Immunol 2002;3:237-243.

35. Nolan KF, Strong V, Soler D, Fairchild PJ, Cobbold SP, Croxton R, Gonzalo JA, Rubio A, Wells M, Waldmann H. IL-10-conditioned dendritic cells, decommissioned for recruitment of adaptive immunity, elicit innate inflammatory gene products in response to danger signals. J Immunol 2004;172:2201-2209.

36. Hoentjen F, Sartor RB, Ozaki M, Jobin C. STAT3 regulates NF-kappaB recruitment to the IL-12p40 promoter in dendritic cells. Blood 2005;105:689-696.

37. Coates PT, Krishnan R, Kireta S, Johnston J, Russ GR. Human myeloid dendritic cells transduced with an adenoviral interleukin-10 gene construct inhibit human skin graft rejection in humanized NOD-scid chimeric mice. Gene Ther 2001;8:1224-1233.

38. Caux C, Massacrier C, Vanbervliet B, Barthelemy C, Liu YJ, Banchereau J. Interleukin 10 inhibits T cell alloreaction induced by human dendritic cells. Int Immunol 1994;6:1177-1185. 
39. Rastellini C, Lu L, Ricordi C, Starzl TE, Rao AS, Thomson AW. Granulocyte/macrophage colony-stimulating factor-stimulated hepatic dendritic cell progenitors prolong pancreatic islet allograft survival. Transplantation 1995;60:1366-1370.

40. Yamaguchi Y, Tsumura H, Miwa M, Inaba K. Contrasting effects of TGF-beta 1 and TNF-alpha on the development of dendritic cells from progenitors in mouse bone marrow. Stem Cells 1997; 15:144-153.

41. Ellingsworth LR, Brennan JE, Fok K, Rosen DM, Bentz H, Piez KA, Seyedin SM. Antibodies to the N-terminal portion of cartilage-inducing factor A and transforming growth factor beta. Immunohistochemical localization and association with differentiating cells. J Biol Chem 1986;261:12362-12367.

42. Strobl H, Knapp W. TGF-betal regulation of dendritic cells. Microbes Infect 1999;1:1283-1290.

43. Zhang Y, Zhang YY, Ogata M, Chen P, Harada A, Hashimoto S, Matsushima K. Transforming growth factor-betal polarizes murine hematopoietic progenitor cells to generate Langerhans cell-like dendritic cells through a monocyte/macrophage differentiation pathway. Blood 1999;93:1208-1220.

44. Mou HB, Lin MF, Cen H, Yu J, Meng XJ. TGF-beta1 treated murine dendritic cells are maturation resistant and down-regulate Toll-like receptor 4 expression. J Zhejiang Univ Sci 2004;5:1239-1244.

45. Tada Y, Asahina A, Fujita H, Mitsui H, Torii H, Watanabe T, Tamaki K. Differential effects of LPS and TGF-beta on the production of IL- 6 and IL-12 by Langerhans cells, splenic dendritic cells, and macrophages. Cytokine 2004;25:155-161.

46. Ogata M, Zhang Y, Wang Y, Itakura M, Zhang YY, Harada A, Hashimoto S, Matsushima K. Chemotactic response toward chemokines and its regulation by transforming growth factor-beta 1 of murine bone marrow hematopoietic progenitor cell-derived different subset of dendritic cells. Blood 1999;93:3225-3232.

47. MartIn-Fontecha A, Sebastiani S, Hopken UE, Uguccioni M, Lipp M, Lanzavecchia A, Sallusto F. Regulation of dendritic cell migration to the draining lymph node: impact on $\mathrm{T}$ lymphocyte traffic and priming. J Exp Med 2003;198:615-621.

48. Fainaru O, Woolf E, Lotem J, Yarmus M, Brenner O, Goldenberg D, Negreanu V, Bernstein Y, Levanon D, Jung S, Groner Y. Runx3 regulates mouse TGF-beta-mediated dendritic cell function and its absence results in airway inflammation. EMBO J 2004;23:969-979.

49. Yarilin D, Duan R, Huang YM, Xiao BG. Dendritic cells exposed in vitro to TGF-betal ameliorate experimental autoimmune myasthenia gravis. Clin Exp Immunol 2002; 127:214-219.

50. Lee WC, Zhong C, Qian S, Wan Y, Gauldie J, Mi Z, Robbins $\mathrm{PD}$, Thomson AW, Lu L. Phenotype, function, and in vivo migration and survival of allogeneic dendritic cell progenitors genetically engineered to express TGF-beta. Transplantation 1998;66:1810-1817.

51. Sun W, Wang Q, Zhang L, Pan J, Zhang M, Lu G, Yao H, Wang J, Cao X. TGF-beta(1) gene modified immature dendritic cells exhibit enhanced tolerogenicity but induce allograft fibrosis in vivo. J Mol Med 2002;80:514-523.

52. Asiedu C, Dong SS, Pereboev A, Wang W, Navarro J, Curiel DT, Thomas JM. Rhesus monocyte-derived dendritic cells modified to over-express TGF-beta1 exhibit potent veto activity. Transplantation 2002;74:629-637.

53. Li MO, Sarkisian MR, Mehal WZ, Rakic P, Flavell RA. Phosphatidylserine receptor is required for clearance of apoptotic cells. Science 2003;302:1560-1563.

54. Cohen PL, Caricchio R, Abraham V, Camenisch TD, Jennette JC, Roubey RA, Earp HS, Matsushima G, Reap EA. Delayed apoptotic cell clearance and lupus-like autoimmunity in mice lacking the c-mer membrane tyrosine kinase. J Exp Med 2002; 196:135-140.
55. Steinman RM, Turley S, Mellman I, Inaba K. The induction of tolerance by dendritic cells that have captured apoptotic cells. J Exp Med 2000;191:411-416.

56. Stuart LM, Lucas M, Simpson C, Lamb J, Savill J, Lacy-Hulbert A. Inhibitory effects of apoptotic cell ingestion upon endotoxin-driven myeloid dendritic cell maturation. J Immunol 2002;168:1627-1635.

57. Kim S, Elkon KB, Ma X. Transcriptional suppression of interleukin-12 gene expression following phagocytosis of apoptotic cells. Immunity 2004;21:643-653.

58. Takahashi M, Kobayashi Y. Cytokine production in association with phagocytosis of apoptotic cells by immature dendritic cells. Cell Immunol 2003;226:105-115.

59. Trinchieri G. Interleukin-12 and the regulation of innate resistance and adaptive immunity. Nat Rev Immunol 2003;3:133-146.

60. Sauter B, Albert ML, Francisco L, Larsson M, Somersan S, Bhardwaj N. Consequences of cell death: exposure to necrotic tumor cells, but not primary tissue cells or apoptotic cells, induces the maturation of immunostimulatory dendritic cells. J Exp Med 2000;191:423-434.

61. Ferguson TA, Herndon J, Elzey B, Griffith TS, Schoenberger S, Green DR. Uptake of apoptotic antigen-coupled cells by lymphoid dendritic cells and cross-priming of CD8(+) T cells produce active immune unresponsiveness. J Immunol 2002;168:5589-5595.

62. Xu DL, Liu Y, Tan JM, Li B, Zhong CP, Zhang XH, Wu CQ, Tang XD. 2004. Marked prolongation of murine cardiac allograft survival using recipient immature dendritic cells loaded with donor-derived apoptotic cells. Scand J Immunol 2004;59:536-544.

63. Basu S, Binder RJ, Suto R, Anderson KM, Srivastava PK. Necrotic but not apoptotic cell death releases heat shock proteins, which deliver a partial maturation signal to dendritic cells and activate the NF-kappa B pathway. Int Immunol 2000;12:1539-1546.

64. Gaipl US, Franz S, Voll RE, Sheriff A, Kalden JR, Herrmann M. Defects in the disposal of dying cells lead to autoimmunity. Curr Rheumatol Rep 2004;6:401-407.

65. Schoenberger SP, Toes RE, van der Voort EI, Offringa R, Melief CJ. T-cell help for cytotoxic T lymphocytes is mediated by CD40-CD40L interactions. Nature 1998;393:480-483.

66. Ridge JP, Di Rosa F, Matzinger P. A conditioned dendritic cell can be a temporal bridge between a CD4 ${ }^{+}$T-helper and a T-killer cell. Nature 1998;393:474-478.

67. Hermans IF, Ritchie DS, Daish A, Yang J, Kehry MR, Ronchese F. Impaired ability of MHC class II-/- dendritic cells to provide tumor protection is rescued by $\mathrm{CD} 40$ ligation. J Immunol 1999;163:77-81.

68. Bennett SR, Carbone FR, Karamalis F, Flavell RA, Miller JF, Heath WR. Help for cytotoxic-T-cell responses is mediated by CD40 signalling. Nature 1998;393:478-480.

69. Zheng Y, Manzotti CN, Liu M, Burke F, Mead KI, Sansom DM. CD86 and CD80 differentially modulate the suppressive function of human regulatory $\mathrm{T}$ cells. J Immunol 2004; $172: 2778-2784$

70. Munn DH, Sharma MD, Mellor AL. Ligation of B7-1/B7-2 by human $\mathrm{CD} 4+\mathrm{T}$ cells triggers indoleamine 2,3-dioxygenase activity in dendritic cells. J Immunol 2004;172:4100-4110.

71. Logue EC, Sha WC. CD28-B7 bidirectional signaling: a two-way street to activation. Nat Immunol 2004;5:1103-1105.

72. Grohmann U, Orabona C, Fallarino F, Vacca C, Calcinaro F, Falorni A, Candeloro P, Belladonna ML, Bianchi R, Fioretti MC, Puccetti P. CTLA-4-Ig regulates tryptophan catabolism in vivo. Nat Immunol 2002;3:1097-1101. 
73. Munn DH, Sharma MD, Lee JR, Jhaver KG, Johnson TS, Keskin DB, Marshall B, Chandler P, Antonia SJ, Burgess R, Slingluff CL Jr, Mellor AL. Potential regulatory function of human dendritic cells expressing indoleamine 2,3-dioxygenase. Science 2002;297:1867-1870.

74. Munn DH, Shafizadeh E, Attwood JT, Bondarev I, Pashine A, Mellor AL. Inhibition of T cell proliferation by macrophage tryptophan catabolism. J Exp Med 1999;189:1363-1372.

75. Grohmann U, Fallarino F, Bianchi R, Belladonna ML, Vacca C, Orabona C, Uyttenhove C, Fioretti MC, Puccetti P. IL-6 inhibits the tolerogenic function of CD8 alpha dendritic cells expressing indoleamine 2,3-dioxygenase. J Immunol 2001;167:708-714.

76. Orabona C, Grohmann U, Belladonna ML, Fallarino F, Vacca C, Bianchi R, Bozza S, Volpi C, Salomon BL, Fioretti MC, Romani L, Puccetti P. CD28 induces immunostimulatory signals in dendritic cells via CD80 and CD86. Nat Immunol 2004;5:1134-1142.

77. Gorczynski RM, Chen Z, Kai Y, Wong S, Lee L. Induction of tolerance-inducing antigen-presenting cells in bone marrow cultures in vitro using monoclonal antibodies to CD200R. Transplantation 2004;77:1138-1144.

78. Fallarino F, Asselin-Paturel C, Vacca C, Bianchi R, Gizzi S, Fioretti MC, Trinchieri G, Grohmann U, Puccetti P. Murine plasmacytoid dendritic cells initiate the immunosuppressive pathway of tryptophan catabolism in response to CD200 receptor engagement. J Immunol 2004;173:3748-3754.

79. Nathan C, Muller WA. Putting the brakes on innate immunity: a regulatory role for CD200? Nat Immunol 2001;2:17-19.

80. Barclay AN, Wright GJ, Brooke G, Brown MH. CD200 and membrane protein interactions in the control of myeloid cells. Trends Immunol 2002;23:285-290.

\section{Author Affiliations}

Mark A. Wallet and Pradip Sen, PhD, Department of Microbiology and Immunology, The University of North

Carolina at Chapel Hill, Chapel Hill, North Carolina 27599.

Roland Tisch, PhD, Department of Microbiology and Immunology, and Lineberger Comprehensive Cancer Center, The University of North Carolina at Chapel Hill, Chapel Hill, North Carolina 27599. 